\title{
PRÁTICA DOCENTE E FORMAÇÃO PROFISSIONAL NA EDUCAÇÃO BÁSICA
}

\section{PRÁCTICA DOCENTE Y FORMACIÓN PROFESIONAL EN LA EDUCACIÓN BÁSICA}

\section{TEACHING PRACTICES AND PROFESSIONAL TRAINING IN BASIC EDUCATION}

Luziane Amaral De Jesus*, Anatália Dejane Silva De Oliveira**

\section{Resumo}

Este artigo objetiva discutir a prática docente no contexto da formação inicial e em serviço de professoras(es) por meio de experiência vivenciada durante estágio supervisionado, considerando a articulação entre teoria e prática no âmbito da Educação Básica. Para tanto, o estudo foi desenvolvido a partir de uma perspectiva metodológica etnográfica. Em primeiro lugar, houve a contextualização da prática docente observada e discussão sobre a alfabetização e os multiletramentos e suas reverberações no processo educativo. Posteriormente, a aula expositiva foi abordada como meio de multiletramentos e produção, circulação e recepção dos gêneros discursivos escolares. As reflexões aqui feitas apontam para a compreensão de que a escola é espaço público de realização da educação escolar e do trabalho

* Licenciatura en Letras, Portugués y Lenguas Extranjeras. Máster en Estudios Lingüísticos. Profesora de Lengua Portuguesa en el Centro de Humanidades de la Universidad Federal del Oeste de Bahía. email: luziane.jesus@ufob.edu.br, ORCID https://orcid. org/0000-0002-4149-2238

** Doctora en Educación, Magister en Educación, Licenciada en Pedagogía. Profesora adjunta del Centro de Humanidades de la Universidad Federal del Oeste de Bahía para el Programa de Licenciatura y Posgrado en Docencia. Coordinadora del Programa de Postgrado en Docencia. email: anatalia@ufob.edu.br, ORCID https://orcid.org/0000-0003-3307-8632 
docente articulado com as(os) participantes que estão dentro e fora dele. Nesse contexto, há dois desafios que perpassam as políticas públicas educacionais que são as condições de trabalho e a formação docente. Mediante estudo realizado, constatamos que a prática docente e a aula expositiva são lugares de enunciação e exigem olhares amplos e múltiplos para entender a complexidade dos processos formativos realizados nos anos iniciais do ensino fundamental.

\section{Palavras-chave:}

Formação de docentes, ensino, aula, docência, educação básica.

\section{Resumen}

Este artículo tiene como objetivo discutir la práctica docente en el contexto de la formación inicial y en servicio de profesoras(es) a través de una experiencia de pasantía supervisada de docentes, considerando la articulación entre teoría y práctica en la Educación Básica. Para eso, la investigación fue desarrollada en una perspectiva metodológica etnográfica. En primer lugar, fue hecha una contextualización de la práctica docente observada y se discute sobre alfabetización y multiliteracidades añadidas y sus reverberaciones en el proceso educativo. Después, la clase expositiva fue abordada como medio de multiliteracidad y producción, circulación y recepción de géneros discursivos escolares. Las reflexiones hechas apuntan a la comprensión de que la escuela es un espacio público de realización de la educación escolar y del trabajo docente articulado con las(os) participantes que están dentro o fuera de él. En ese contexto, hay dos retos en las políticas públicas educacionales, estos son ellos: las condiciones de trabajo y la formación docente. Mediante la realización de esta investigación comprendemos que la práctica docente y la clase expositiva son lugares de enunciación y exigen miradas amplias y múltiples para entender la complejidad de los procesos formativos realizados en los años iniciales de la enseñanza primaria.

\section{Palabras clave:}

Formación de docentes, enseñanza, clase, docencia, educación básica. 


\begin{abstract}
This paper aims to describe and discuss teaching practices in the context of initial training and in service of teachers through experiences lived during Student Teaching practices, considering the articulation between theory and practice in the scope of Basic Education. Therefore, the study was developed from an ethnographic methodological perspective. Firstly, there was a contextualization of the observed teaching practice and a discussion on literacy and multiliteracies and their reverberations in the educational process and in the production, circulation and reception of discursive genres. Later, expository classes (lectures) were presented as a means of multi-literacy and production, circulation and reception of school discourse genres. The reflections made here point to the understanding that school is a public space for carrying out education and teaching. It's also a space articulated with the participants who are inside and outside of it. In this context, there are two challenges that pervade public educational policies, which are working conditions and teacher training. Through this study, we found out that teaching practices and expository classes (lectures) are places of enunciation and require broad and multiple views to understand the complexity of the formative processes carried out in the early years of elementary school.
\end{abstract}

\title{
Keywords:
}

Teacher education, Teaching, Classrooms, Teaching process, Basic education.

\section{Introdução}

$\mathrm{N}$ as últimas décadas, há uma preocupação latente em compreender como a formação docente inicial e continuada impacta nas práticas das(os) profissionais da Educação Básica e Superior. Diante disso, este estudo objetiva discutir a prática docente em instituições públicas de ensino, a partir de uma experiência vivenciada por professoras(es) da Educação Básica, especificamente nos anos iniciais do Ensino Fundamental.

Este artigo apresenta a experiência vivenciada, no período de 
três anos entre 2008 a 2010, por um grupo de 33 (trinta e três) docentes concursadas(os), atuantes em uma rede pública de ensino, nos primeiros anos do Ensino Fundamental $\left(1^{\circ}\right.$ ao $\left.5^{\circ}\right)$, em escolas localizadas na zona urbana e, principalmente, na zona rural. Essas(es) professoras(es) participaram de um programa de formação inicial em serviço, para a obtenção da graduação em Pedagogia.

Na primeira seção, contextualizamos o ambiente de pesquisa em que a prática docente é vista a partir de uma experiência de estágio supervisionado, vivenciada por professoras(es) em exercício do magistério, enveredando pela relação entre teoria e prática na formação docente no âmbito da Educação Básica. A seção dois apresenta a perspectiva metodológica do estudo. Na seção três, discutimos a alfabetização e os multiletramentos e suas reverberações no processo educativo e na produção, circulação e recepção dos gêneros discursivos. A seção penúltima aborda a aula expositiva como meio de multiletramentos e produção de gêneros discursivos em escolas públicas participantes do estudo. Por fim, compreendemos que a prática docente e a formação continuada estão imbricadas e em constante movimento pela dinâmica do trabalho escolar.

\section{Contextualização}

A escola pública é uma instituição social responsável pela implementação da educação escolar no âmbito das etapas e modalidades da Educação Básica, mediante a promoção de processos formativos que se dão a partir de trocas sociais, partilhas e descobertas. Nesse contexto, a prática docente tem sido historicamente marcada por muitos desafios e também muitas conquistas.

Entre os principais desafios, na realidade da escola pública brasileira, destacamos a formação continuada de professoras(es), as condições de trabalho em articulação com as experiências sociais dos sujeitos envolvidos no processo educativo e a (res)significação das relações de ensino e aprendizagem, bem como dos movimentos formativos.

No que tangem às conquistas, uma delas é o Programa Intensivo 
de Graduação Rede UNEB 2000 -proposto e realizado pela Universidade do Estado da Bahia- foi implementado mediante parcerias firmadas entre essa Universidade e prefeituras municipais do estado da Bahia, visando graduar docentes da rede pública em cursos de licenciaturas, em atendimento ao estabelecido na Lei de Diretrizes e Bases da Educação Nacional, Lei nº . 9394/1996 (Congresso Nacional, 1996).

Em 2017, ainda 23,6\% das(os) professoras(es) dos anos iniciais do Ensino Fundamental possuíam ensino médio.

Tabela 1. Escolaridade da(o) docente nos anos iniciais do Ensino Fundamental 2017

\begin{tabular}{lccc}
\hline \multicolumn{1}{c}{ Níveis de formação } & Educação Básica & Anos Iniciais \\
\hline \multirow{2}{*}{2017} & 1.281 & 442 \\
Fundamental incompleto & 3.985 & 1.211 \\
Fundamental completo & 443.695 & 179.451 \\
Ensino Médio & 1.629 .949 & 580.633 \\
Superior & $\mathbf{2 . 0 7 8 . 9 1 0}$ & $\mathbf{7 6 1 . 7 3 7}$ \\
\hline
\end{tabular}

Fonte: Carvalho, 2018. [Adaptado].

Mediante a realidade apresentada, é possível reconhecer que a existência e implantação do Programa Rede UNEB 2000 foi fundamental para licenciar professoras(es) que possuíam formação em ensino médio, provocando impacto significativo na política de formação docente no sistema público de ensino da Bahia e, consequentemente, no trabalho docente das escolas de Educação Básica.

Nos cursos de licenciatura, o estágio supervisionado pode ser entendido como tempo-espaço de formação com características que podem auxiliar na reflexão sobre a prática, ao possuir como campo de conhecimento as pesquisas nas áreas da pedagogia e da didática, a relação ensino e pesquisa desenha-se à medida em que se aprende e se ensina (Pimenta e Lima, 2019).

A dinâmica formativa vivenciada no estágio supervisionado é 
caracterizada pela dialogicidade promovida entre as convivências no ambiente de formação acadêmico-profissional e aquelas constituídas na escola, lócus de atuação docente, a partir do trabalho conjunto entre as professoras-formadoras da Universidade e as(os) docentes-estudantes da licenciatura em Pedagogia. Assim, as práticas docentes ocorreram mediante observação e acompanhamento das atividades profissionais desenvolvidas nas escolas públicas, seguida de diálogos, estudos, análise, problematização, reflexão e proposição para a realidade escolar observada. Ou seja, a prática profissional das(os) professoras(es) nas escolas consistia em atividade formativa no curso de licenciatura e, portanto, era contabilizada como carga horária destinada ao estágio curricular.

É importante registrar que esse arranjo formativo trata-se de um ato histórico, em uma relação de tempo e espaço particular de sujeitos que se encontram, no campo da formação de professores, com o propósito comum de significar o trabalho escolar a partir das aprendizagens de docentes e estudantes, uma vez que as atividades de estágio supervisionado eram desenvolvidas por profissionais da Educação Básica já em exercício do magistério, na condição de servidoras(es) públicas(os) de uma rede de ensino municipal, cujo lócus de trabalho também era ambiente de formação. Essa dinâmica é singular porque coloca o estágio supervisionado como campo de investigação e princípio de veridicidade na articulação entre teoria e prática.

As experiências de estágio constroem, portanto, o sensível e o inteligível a partir da relação entre teoria e prática, constituindo um desafio necessário na produção de sentidos entre ambos nos cursos de formação docente, mas também no lócus de atuação de professoras(es). Desse lugar, surgem essas indagações: teoria e prática podem ser colocadas em oposições binárias? A prática é estranha à teoria e vice-versa? Por que e de que forma essas fronteiras são produzidas na formação e atuação de professoras(es) nos anos iniciais do Ensino Fundamental no contexto da escola pública?

$\mathrm{Na}$ perspectiva da racionalidade técnica, historicamente, a formação inicial tem se ocupado no campo do ensino em produzir antecipações, promover previsibilidades do ato educativo para um 
tempo futuro, criando para si a responsabilidade de, por um lado, inventar para a escola uma(um) docente idealizada(o) para se apropriar de valores e saberes predeterminados e, de outro lado, esse ato em si coloca a escola no lugar de continuar reforçando uma expectativa de que é nela que estudantes se formam como cidadãos para uma sociedade desejada, projetada.

Esse jogo iluminista de atribuição de responsabilidades mútuas -acordado entre a escola e a sociedade para a produção de sujeitos desejáveis pela apropriação de conhecimentos que estão fora deletem envolvido as experiências de formação de professoras(es) nas instituições de ensino superior. Nesse jogo, o currículo da formação tem servido mais como instrumento de controle sobre 'o que vale a pena ser ensinado', na condição de guardião do papel da escola e na vanguarda das práticas docentes para anunciar 'como ensinar esse conhecimento a alguém'. No entanto, experiências de formação em serviço podem romper essa lógica de linearidade e continuidade, (Pinar, 2016), atribuída aos processos de ensino e aprendizagem nos contextos da formação e atuação docente.

Ao assumir a escola como espaço público de sociabilidade, (Macedo, 2019), as experiências docentes podem nos oferecer um importante contexto de significações para problematizar o sentido prescritivo assumido nos cursos de formação de professores, amparados nos princípios da normatividade. Nessa relação entre o sensível e o inteligível, existe uma luta política produzida pelas vivências escolares que (res)significam a função social da escola.

Nos cursos de formação de professores em que há busca de superação de fronteiras entre teoria e prática em diálogo com a realidade da escola da Educação Básica, há como se desvincular essas concepções das políticas neoliberais. De modo geral, o rompimento dessas fronteiras pode deslocar a escola do lugar de como ensinar algo a alguém e de preparação para saber definir, no futuro, os processos de ensino e aprendizagem em que estudantes serão submetidos para responder ao desejado sucesso escolar. Desmonta-se, assim, o entendimento de que o ensino tem forma e conteúdo predeterminado, abrindo possibilidades para compreendê-lo no campo da educação pela relação de alteridade e dialogismo em 
processo permanente de negociação entre pessoas que agem em momentos circunstanciais, provisórios e precários.

Essa provocação feita nos cursos de formação de professoras(es) no sentido de (res)significar o ensino, na relação teoria e prática, funciona como uma recusa a dar consentimentos ao outro sobre como fazer ou não fazer o trabalho escolar. Pelo contrário, a ação produtora de sentidos se abre para o inconstante e a imprevisibilidade e se coloca em movimento na desconstrução de certezas e verdades em torno do ato de ensinar. Assim, a relação entre teoria e prática na formação docente para a Educação Básica emana múltiplas possibilidades de enunciações, que se traduzem no ato de conhecer e de educar sujeitos sociais, históricos e culturais.

Nesse âmbito, é preciso resgatar o pressuposto de que os enunciados concretos são produzidos dentro de um campo da atividade humana e tem um lugar na sociedade e história, isto é, os sujeitos sempre estão interagindo com outros sujeitos desde uma perspectiva ideológica, na qual o signo está carregado de sentidos que emanam de uma posição social, história e cultural (Bakhtin, 2011).

Essa possibilidade de (res)significação da relação entre teoria e prática nos cursos de formação de professores pode dar novos sentidos ao trabalho docente, deslocando a preocupação tão comum entre professoras(es) na questão "como vou fazer para o aluno aprender?", para outra interconexão: agir em dinâmicas sociais de produção de sentidos em que as(os) estudantes decidem sobre “o que fazer com o que estou aprendendo?". Percebemos que a relação pedagógica produzida nesse movimento é uma composição discursiva, uma sociabilidade política significada no tempo-espaço do ato de conhecer pela ação de quem se produz nesse processo. A dimensão pedagógica, então, tem intencionalidade educativa em que ser estudante é efeito do conhecer e saber produzidos nas relações sociais estabelecidas.

Desse modo, compreendemos que, nas atividades de estágio supervisionado, a relação dialógica entre teoria e prática pode ser ressignificar a dimensão pedagógica, porque, sob essa perspectiva, professoras(es) agem diante dos problemas produzidos na realidade escolar e enfrentados nas práticas docentes no exercício do devir 
do ato de conhecer, diante do imprevisível, do estranho, do desconhecido nos processos sociais. Assim, seria possível, nos cursos de formação de professores, a interação teoria e a prática produzir uma relação dialógica e pedagógica, simultaneamente.

Então, o trabalho docente, na relação pedagógica, produz uma ação política na busca de sentidos em um contínuo processo de negociação em torno do ato de conhecer que se faz pela troca de experiências e discursividades. Essa relação é efeito da produção de sujeitos socialmente situados.

$\mathrm{Na}$ perspectiva bakhtiniana, o enunciado ocupa uma posição definida em uma dada esfera da comunicação, em uma dada questão, em um dado assunto. É impossível alguém definir sua posição sem correlacioná-la com outras posições, pois "cada enunciado é pleno de variadas atitudes responsivas a outros enunciados de dada esfera da comunicação discursiva" (Bakhtin, 2011, p.297).

Por isso, no contexto da formação de professores, esse diálogo dá sentido ao trabalho docente porque amplia espaços de decisão, possibilitando assumir responsabilidades e posições políticas na produção de sujeitos de poder. Esse diálogo se produz porque teoria e prática são processos político-pedagógicos constitutivos da atuação docente. E, além disso, a relação pedagógica, como ação política, amplia as possibilidades de produção de sentidos do ato de conhecer. Ela pode ser reconhecida como uma realidade produzida na relação social por um sujeito que pensa e atua no fazer coletivo. Se a ação só é possível na relação, logo, esta é sempre produzida com $\mathrm{a}(\mathrm{o})$ outra(o), que revela a si própria(o) e, nessa revelação, produz sentidos de existência consigo mesma(o) e com as(os) outras(os).

\section{Perspectiva metodológica}

Trabalhamos com a abordagem qualitativa com pesquisa do tipo etnográfica por reconhecermos que a pesquisa realizada, neste estudo, envolve a observação do contexto de atuação profissional como qualificador das múltiplas formas de apropriação de informações que visam produção de conhecimentos no âmbito educacional. Esta 
pesquisa se torna, portanto, uma experiência em que os sujeitos "vivem o presente marcado pelo passado e projetado para o futuro, num embate constante entre o que está dado e o que está sendo construído. Portanto, a provisoriedade, o dinamismo e as especificidades são características fundamentais" (Minayo, 2016, p.13).

Em diálogo com a autora e com base numa experiência de formação docente na Educação Básica, descrevemos como esse contexto estudado envolve a convivência e a partilha de saberes na relação teoria e prática, tendo o desafio de traduzir os mistérios nele presentes, especialmente por meio de aulas expositivas. Para tanto, utilizamos os dados que foram coletados no período de 2008 a 2010, durante as vivências no curso de Pedagogia, no âmbito do Programa Intensivo de Graduação Rede UNEB 2000, o qual foi instituído por meio de parceria entre a Universidade e o município baiano contemplado nesse estudo, tendo como objetivo graduar professoras(es) da rede pública de ensino não licenciadas(os).

Nesse contexto, o estágio supervisionado vivenciado pelas(os) professoras(es) consistiu numa ação formativa singular porque ocorria durante os três anos do curso e promovia a articulação entre as experiências acadêmicas e o trabalho docente, como formação inicial e continuada. Às docentes-formadoras da Universidade, competia a responsabilidade pelo acompanhamento e orientação acadêmico-profissional, mediante um conjunto de ações que se pautava em observações periódicas das aulas ministradas pelas(os) licenciandas(os)-docentes e preenchimento de fichas específicas, nas quais eram protocoladas todas as informações a partir de três aspectos:

a) Tipos de ação docente desenvolvida, ou seja, o que se realizava em sala de aula (regência, tipo de aula, trabalho de campo, reuniões);

b) prática pedagógica que evidenciava como a atividade estava sendo desenvolvida (projeto/planejamento; mediação; postura; relacionamentos);

c) comentários, recomendações e proposições das docentes-formadoras para as(os) licenciandas(os). 
Essas fichas eram compartilhadas com as(os) docentes-estudantes do curso de Pedagogia no interstício temporal entre uma observação e outra para que pudessem refletir sobre as próprias práticas pedagógicas e, a partir disso, rever, aprimorar e tomar consciência epistemológica e metodológica do próprio fazer docente. Nessas fichas estão os dados que amparam a nossa discussão sobre a prática docente nos anos iniciais do Ensino Fundamental em instituições públicas de ensino baianas e brasileiras. Portanto, estamos revisitando os dados após uma década dessa experiência e analisando-os numa perspectiva qualitativa de cunho etnográfico. Esse exercício nos faz perceber o quanto todas as pessoas estavam imbuídas de um compromisso político em defesa da qualidade da educação pública, em permanente diálogo entre teoria e prática e suas reverberações no contexto escolar.

Durante a análise dessas fichas, observamos a predominância da aula do tipo expositiva, o que nos levou a refletir como essa modalidade de aula viabiliza a prática docente e, ao mesmo tempo, impacta nos letramentos das(os) estudantes e demais participantes do processo educativo. Com base no conceito de multiletramentos de Rojo (2012, 2014 e Barbosa, 2015) e nas discussões sobre linguagem dos intelectuais do Círculo de Bakhtin (2011 e 2017), discutimos a aula expositiva como modus operandi de letrar as(os) discentes no espaço escolar, especificamente nessa realidade observada, uma vez que os letramentos ocorrem por meio dos gêneros discursivos.

Para tanto, esta abordagem de investigação consiste num estudo de caso do tipo etnográfico, porque objetiva refletir sobre a produção da prática docente nos processos de ensino e aprendizagem dentro de um contexto cultural amplo (Lüdke e André, 2016), no qual há estudantes que vivenciam o cotidiano da agricultura e pecuária de produção e consumo próprios, bem como há aqueles que têm suas experiências restritas à vida urbana. De outro lado, também estão as(os) docentes que visam exercer suas práticas considerando essa complexidade. Portanto, trata-se de uma realidade complexa no âmbito de um município localizado na macrorregião do oeste da Bahia. 


\section{As reverberações da realidade escolar na formação docente}

Neste estudo, todas(os) as(os) docentes participantes desenvolveram as atividades de estágio supervisionado no exercício do magistério na própria escola de atuação como profissionais da Educação Básica e foram observadas(os) pelas professoras-orientadoras em dias, escolas e áreas distintas, conforme quadro a seguir:

Tabela 2. Dados gerais da pesquisa.

\begin{tabular}{ccccccc}
\hline \multirow{2}{*}{$\begin{array}{c}\text { Total de } \\
\text { escolas }\end{array}$} & $\begin{array}{c}\text { Total de } \\
\text { turmas }\end{array}$ & \multicolumn{2}{c}{ Localização das turmas por escola } & \multicolumn{2}{c}{ Docentes } \\
& Urbana & Rural & Entrelugar & Feminino & Masculino \\
\hline \multirow{2}{*}{15} & \multirow{2}{*}{33} & 6 & 11 & 16 & 26 & 7 \\
\cline { 3 - 7 } & & & & Total: 33 & & Total: 33 \\
\hline
\end{tabular}

Com base na tabela apresentada, as escolas observadas englobam trinta e três turmas, as quais estão localizadas nas áreas urbana, rural e de entrelugar. Este corresponde a escolas/turmas que não estão totalmente inseridas em uma das duas primeiras áreas, mas também são espaços que partilham das duas vivências: urbana e rural. Portanto, os saberes são construídos e produzidos a partir da interface entre essas duas especificidades. Desse modo, as práticas das(os) professoras(es) dessas escolas/turmas de entrelugar não funcionam como as exercidas nas localidades rurais ou urbanas.

As escolas da área urbana ficam na sede do município participante desse estudo. Nela, concentram-se as instalações físicas dos órgãos governamentais (poderes legislativo, executivo e judiciário, hospital, secretarias da gestão municipal), comércio varejista, terminal rodoviário interestadual etc. Isso facilita o acesso das(os) estudantes a esses espaços de produção de conhecimentos e saberes. Na prática docente, essa realidade favorece o estabelecimento da relação entre a vida da/na cidade e a escola.

Nas escolas da localidade rural, as experiências se dão por meio do contato com a natureza e as vivências do povo do campo. Além disso, as instalações físicas dessas instituições de ensino 
são precárias e os materiais didático-pedagógicos e de tecnologias de informação e comunicação são inexistentes, resultando num maior comprometimento tempo-espaço pedagógico e provocando certa intensificação do trabalho docente voltada a poucos recursos tecno-pedagógicos: caderno, livro didático, quadro de giz, apagador e o próprio giz. Daí a importância de abordá-las separadamente, pois as situações e os modos de ensinar e aprender são distintos.

Para além das áreas abarcadas pela escola, traçamos também o perfil de sexo das(os) docentes observadas(os). Diante dos dados, podemos afirmar que o magistério, nesta rede municipal de ensino, está sendo assumido, predominantemente, por pessoas do sexo feminino. Este fenômeno não é novo! As relações produzidas entre o magistério e o feminino têm demarcado a produção de políticas educacionais, sobretudo, de formação docente.

Transcorrida quase uma década do levantamento de dados deste estudo, em 2017, o Censo Escolar, tratando do perfil das(os) professoras(es) da Educação Básica, nos anos iniciais do Ensino Fundamental ( $1^{\circ}$ ao $5^{\circ}$ ano), aponta, em seus dados, 677.219 docentes do sexo feminino ( $89,9 \%$ do total) e 84.518 docentes do sexo masculino, correspondendo a 11,1\% do total (Carvalho, 2018). Portanto, a feminização do magistério é uma realidade histórica no Brasil, e junto com ela estão intensas e continuadas lutas e enfrentamentos em prol da melhoria da qualidade da Educação Básica.

Neste nível educacional, a necessidade de políticas de profissionalização que assegurem direitos e condições satisfatórias de trabalho, formação inicial e continuada, remuneração digna, reconhecimento e valorização das profissionais docentes é latente. Para além da feminização do magistério, há também o fenômeno da distorção idade-série, conforme a tabela a seguir:

Tabela 3. Estudantes participantes

\begin{tabular}{cccc}
\hline $\begin{array}{c}\text { Total de } \\
\text { turmas }\end{array}$ & $\begin{array}{c}\text { Turmas com dis- } \\
\text { torção idade-série }\end{array}$ & Matutino & Estudantes \\
\hline \multirow{2}{*}{33} & 24 & 946 & Vespertino \\
\cline { 3 - 4 } & \multirow{2}{*}{24} & & Total: 1798 \\
\hline
\end{tabular}


Das turmas observadas, 73\% delas possuem estudantes com distorção idade-série (311 - 17,3\%). Diante disso, as experiências de vida sociais e culturais desses discentes deveriam ser contempladas na implementação da prática pedagógica. Por exemplo, nas atividades propiciadas pelas(os) professoras(es), há a necessidade de contemplar realidades diversas, envolvendo a infância e a adolescência, pois elas estão em sala de aula e se encontram em um tempo-lugar e momentos de vida distintos, mas têm os mesmos objetivos, dentre eles: aprender, partilhar e produzir conhecimentos e saberes no âmbito da educação escolar.

Mediante a apresentação das escolas, é possível observar os efeitos advindos dessa complexa realidade na formação inicial e em serviço, bem como na prática docente, em conformidade com o contexto que vem sendo discutido aqui. Diante disso, entendemos que a viabilização de uma multiplicidade de práticas de alfabetização e multiletramentos nas escolas pode ser um dos meios de abarcar diversas realidades e intencionalidades educativas vivenciadas nos processos de ensino e aprendizagem.

\section{Alfabetização e multiletramentos nos anos iniciais do ensino fundamental}

Do ponto de vista das políticas educacionais, nos três primeiros anos iniciais do Ensino Fundamental, a alfabetização é uma das prioridades do trabalho pedagógico realizado na escola da Educação Básica. Por que ela é tão importante? Ela é a principal ferramenta social de constituição do processo de emancipação e transformação social das(os) estudantes.

A alfabetização é muito mais do que um ato de decodificação, codificação e transcrição de sons e letras. Nos anos iniciais do Ensino Fundamental, ela produz significado quando a criança é colocada para agir/refletir sobre a língua, entendendo-a como cultura, produtora de linguagens, diversidades, reconhecimento de si e da(o) outra(o) no mundo; é representação; é processo de estabelecimento de relações.

Além disso, a alfabetização é um ato político, como nos aponta Freire (2017, p.16), ao defender que “[...] o processo de alfabetização 
política -como o processo linguístico- pode ser uma prática para a "domesticação dos homens", ou uma prática para sua libertação". Somente em ação educativa libertadora se produz a conscientização. Portanto, alfabetizar politicamente é preciso!

No âmbito dos estudos da linguagem, desde a década de 1990, usa-se o termo letramento para abarcar essa concepção freireana de alfabetização. Deste modo, a aprendizagem da leitura, escrita, oralidade e multissemioses possui uma natureza política, ou seja, o alfabetismo se torna instrumento promotor da mudança social e, portanto, ele é essencialmente político (Soares, 2018).

Esse processo de alfabetização numa dimensão política é uma responsabilidade coletiva de produção histórico-social e cultural. Como instituição social, a escola compartilha com o Estado e a família da responsabilidade do acompanhamento desse trabalho de alfabetização política. Um dos desafios contemporâneos é a superação da ideia de que o professor é o único que deve se ocupar nesse/ desse processo.

A escola, a família e a sociedade são corresponsáveis pela educação de suas(seus) estudantes-filhas(os)-cidadãs(ãos), uma vez que elas(es) são sujeitos de cultura que vivem e se constituem em contextos sociais de interação. Isto significa dizer que a convivência coletiva na sociedade precisa propiciar de forma equânime o acesso de todas as pessoas aos bens culturais produzidos historicamente por todas(os) nós, de maneira a reconhecer que crianças, adolescentes, jovens e adultos têm direito de acessar tudo o que produzimos social e culturalmente. Essa experiência precisa ser apropriada pelo trabalho escolar para qualificar as aprendizagens individuais e coletivas dentro e fora da escola. Nessa conjuntura, os processos de alfabetização se tornarão dialógicos pelo trabalho da educação escolar, correlacionando, assim, a constituição da trajetória de vida das pessoas com as demandas da sociedade contemporânea.

Após acompanhamento e orientação das aulas observadas, nos protocolos, identificamos a predominância das aulas de Língua Portuguesa (52), em detrimento das demais áreas de conhecimento e componentes curriculares que integram o currículo escolar nos anos iniciais do Ensino Fundamental, ressaltamos que também 
houve 7 (sete) aulas que envolviam Língua Portuguesa, mas não como protagonista. Essa constatação é uma realidade presente na educação escolar pública em que há uma transferência e localização estrita ao componente curricular de língua(gem) como o único responsável pelos processos de alfabetização e multiletramentos. No entanto, esse processo formativo precisa acontecer no conjunto dos componentes curriculares e por meio de distintas práticas sociais de leitura, escrita, oralidade e múltiplas semioses. Nesse estudo, compreendemos a prática docente como trabalho de produção da educação escolar, predominantemente, por meio da aula expositiva. Diante disso, seria importante que a escola, como projeto político de poder, assumisse a pedagogia dos multiletramentos na prática educativa.

A pedagogia dos multiletramentos solicita da escola a tomada para si de uma discussão crítica das "éticas" ou costumes locais, constituindo uma ética plural e democrática, capaz de problematizar criticamente as distintas "estéticas", instituindo critérios críticos diversos de apreciação dos produtos culturais locais e globais (Rojo, 2012).

Nesse caso, as propostas de ensino e aprendizagem deveria considerar os "letramentos múltiplos, ou multiletramentos, abrangendo leitura crítica, análise e produção de textos multissemióticos em enfoque multicultural" (Rojo, 2014, p.8).

No caso desse estudo, o diálogo entre campo e cidade, ruralização e urbanização, agricultura e indústria. Nesse ínterim, as práticas docentes deveriam interagir com as experiências de vida das(os) estudantes em sua dinâmica social. Por exemplo, nas escolas localizadas em áreas rurais, seria pertinente apropriar-se das práticas cotidianas culturalmente produzidas como criação de animais domésticos, plantio de frutas, legumes, verduras e sementes, bem como torra e moagem do café, secagem e debulhar do feijão, cantigas de reis, sambas de roda, ocupação do plantio e uso de ervas medicinais, rezas e suas rezadeiras, vaquejadas, cavalgadas etc.

Ao praticar a pedagogia dos multiletramentos, aquela concentração de aulas no componente curricular de Língua Portuguesa deixaria de existir, pois compreenderíamos que a alfabetização 
como ato político (multiletramentos) não se restringe a esse componente. No entanto, essa concentração sinaliza uma complexa realidade social enfrentada pela educação escolar, que é o baixo nível de alfabetização entre os estudantes que estão concluindo os anos iniciais do Ensino Fundamental. Nesse sentido, há sim um esforço no trabalho docente em criar dinâmicas formativas para ampliação das práticas de leitura, escrita, oralidade e multissemioses como promotoras de processos de alfabetização. Esse esforço pode ser superado, conjuntamente na escola, por meio da promoção de atividades inter e transdisciplinares, na qual a prática docente passa a ser vivida em sua totalidade e complexidade.

Diante disso, percebe-se que os multiletramentos se voltam para as trocas culturais, ou seja, para a diversidade e a pluralidade cultural trazida pelos autores e leitores dos textos contemporâneos em sintonia com a multiplicidade de linguagens, semioses e mídias involucradas na criação e significação dos gêneros discursivos/ discursos/textos.

O conceito de multiletramentos, desse modo, abarca multimodalidade e multiculturalidade (letramento digital, letramento visual, novos letramentos etc), contextos e domínios socioculturais específicos e diferenciados (letramento escolar, familiar, acadêmico, literário etc) e diversidade e pluralidade cultural ou multiculturalidade (letramento local, vernacular, global, dominante, etc). Ou seja, os multiletramentos - letramentos múltiplos, letramentos multissemióticos e letramentos críticos e protagonistas - visam dar conta da heterogeneidade das práticas sociais letradas contemporâneas, envolvendo o uso dos gêneros discursivos multimodais.

A imensidão de gêneros do discurso, a multiculturalidade e as múltiplas e complexas práticas de letramentos das sociedades impelem veementemente a escola a abandonar o trabalho com os tipos textuais, os quais podem ser facilmente delineados, mas nunca podem ser concebidos como gêneros do discurso e assumir o trabalho com os gêneros discursivos como modo político de transformação da realidade social, política e cultural dos estudantes. 


\section{Aula expositiva e gêneros discursivos na escola}

Nessa seção, visamos compreender como a formação e atuação de professoras(es) nos anos iniciais do Ensino Fundamental produzem o contexto formativo da/na escola pública, uma vez que nossas práticas sociais, políticas, culturais e discursivas são exercidas por meio da linguagem dentro da sociedade, portanto, há aqui uma relação mútua e intrínseca entre ambas.

De acordo com Bakhtin (2017), a língua(gem) é um fenômeno social; é na fala que ratificamos a natureza social da língua por meio da interação verbal, concretizada nas enunciações de natureza social, logo, a realidade fundamental da língua é a interação verbal. É por meio dos enunciados que constituímos os discursos, os quais são materializados nos gêneros discursivos nas diversas esferas da atividade humana.

Segundo Lemke (2010), "um letramento é sempre um letramento em algum gênero e deve ser definido com respeito aos sistemas sígnicos empregados [..]". No nosso estudo, resultado da experiência de observação do Estágio Supervisionado nos anos iniciais do Ensino Fundamental, o gênero discursivo de maior frequência na prática docente foi a aula expositiva. Portanto, os multiletramentos ocorreram por meio, especialmente, desse gênero discursivo de natureza mista, pois ele envolve as modalidades escrita e oral da língua.

Mediante esse contexto, consideramos pertinente discutir a aula expositiva como viabilizadora do diálogo entre teoria e prática, problematizando-a em interface com as possíveis questões imbricadas na convivência cotidiana dos processos de ensino e de aprendizagem constituídos nessa repetição, no âmbito da Educação Básica e como lugar de produção de outros tantos gêneros discursivos.

Como todo e qualquer gênero discursivo, a aula expositiva é uma enunciação que dialoga com as condições de produção, circulação e recepção de discursos, pois está inteiramente determinada "[...] pelas relações de produção e pela estrutura sócio-política" (Bakhtin, 2017, p.42).

A predileção pela aula expositiva se dar, principalmente, por causa da especificidade da esfera de atividade e de circulação de 
discurso: a escola. Ela (agência educativa, científica e acadêmica) possui a incumbência de ensinar as práticas sociais de escrita, leitura, oralidade e múltiplas semioses às(aos) estudantes, ou seja, cabe às(aos) professoras(es) esse desafio, e uma das formas de cumpri-lo é por meio da viabilização de aulas que deem conta dessa especificidade, bem como de discussões pertinentes e voltadas à realidade do entorno escolar.

Na aula expositiva, (Pereira, 2012), as falas das(os) professoras(es) apresentam tanto o que foi planejado antecipadamente quanto o que será vivenciado mediante o diálogo estabelecido no acontecimento desse gênero. Desse modo, conforme a autora, há uma oscilação entre o planejado e o não planejado, uma vez que o discurso do(a) professor(a), bem como os propósitos intencionais desse discurso (proveniente do que foi planejado antecipadamente) se entrelaçam com as intenções oriundas das(os) suas(seus) interlocutoras(es) -as(os) estudantes- a partir da temática abordada. Portanto, o discurso é efetivado no encontro entre as reflexões e conclusões da(o) docente com a negociação de sentido construída em sala de aula junto às(aos) discentes.

Também é pertinente salientar que os sujeitos envolvidos, no processo educativo, são reconhecidos como produtores de cultura e de suas ações sobre ela, melhor afirmando, esses sujeitos ao mesmo tempo em que repetem atos e gestos, eles constroem novos atos e gestos, ou seja, a repetição e a criação andam juntas (Geraldi, 2013). Por isso, é importante compreender como esses interlocutores, envolvidos por esse gênero discursivo, produzem suas interações verbais no cotidiano escolar a partir da aula expositiva.

Nas escolas públicas observadas, um dos seus maiores entraves nos anos iniciais do Ensino Fundamental é a distorção idade-série das(os) discentes, resultante das múltiplas repetências e da evasão escolar, mas também do analfabetismo funcional e da pouca (con)vivência com múltiplas práticas de letramentos. Esse contexto social influencia diretamente nas escolhas pedagógicas do trabalho das(os) professoras(es). Associado a isso, estão as precárias condições de trabalho oferecidas às(aos) professoras(es) nas instituições educacionais observadas, sendo materializadas, 
principalmente, pela limitada disponibilização de recursos didático-pedagógicos, os quais também subsidiam as escolhas das(os) professoras(es) no fazer docente.

Tabela 4. Prática docente observada

\begin{tabular}{|c|c|c|c|c|}
\hline \multicolumn{2}{|c|}{ Observações } & \multirow{2}{*}{\multicolumn{3}{|c|}{$\begin{array}{c}\text { Materiais utilizados } \\
\text { Número de ocorrências }\end{array}$}} \\
\hline Quantidade & Tempo & & & \\
\hline \multirow{2}{*}{80} & \multirow{2}{*}{$160 \mathrm{~h} / \mathrm{a}$} & Quadro de giz & Caderno & Livro didático \\
\hline & & 43 & 34 & 26 \\
\hline
\end{tabular}

Os recursos utilizados pelas(os) professoras(es) nos processos formativos, em sala de aula, como se pode ver na tabela acima, em interface com a quantidade de aulas e tempo de observação demonstra a escassez de recursos presentes na maioria das escolas participantes deste estudo. Isso impacta, diretamente e indiretamente, no trabalho docente, no qual a inventividade e a criatividade são inibidas, resultando na rotinização dos processos formativos das(os) estudantes.

Essa pouca disponibilidade de material didático e a inexistência de tecnologias da informação e comunicação somadas ao imaginário social têm produzido, historicamente, no contexto escolar, o entendimento de que a quase exclusividade na proposição de atividades que envolvem leitura e escrita é o meio necessário para os multiletramentos de crianças e adolescentes, estejam elas ou não em distorção idade/série. Por exemplo, as famílias acreditam que o grande volume de atividades escritas diariamente no caderno é uma demonstração da aprendizagem escolar significativa de seus familiares aprendentes.

Pressões sociais e institucionais dessa natureza acrescidas da inquietação das(os) professoras(es) e as disputas latentes entre as concepções de língua(gens), ensino, escola, professor(a) e da própria aula per si presentes no cotidiano escolar também fazem com que a aula expositiva seja o ambiente privilegiado da relação entre docentes e estudantes nos processos de ensino e aprendizagem. Querendo 
ou não, essas dinâmicas impactam na prática docente, inclusive na escolha do tipo de aula, pois a aula expositiva é a que mais possibilita o uso constante daqueles recursos mais utilizados e daquele tipo de atividade vista como "ideal para aprender e ensinar". Essa realidade pode ser também reconhecida no uso recorrente de determinados gêneros discursivos na escola, conforme os dados a seguir.

Nas aulas expositivas, identificamos 37 (trinta e sete) gêneros discursivos vivenciados por meio de 129 (cento e vinte e nove) ocorrências: atividade escolar, bandeira, bingo, biografia, brincadeira, carta, cartão natalino, cartaz, charge, contação de história, conto, conversação, cruzadinha, desenho, diário escolar, fábula, história infantil, imagem, jogos, jogral, lista de palavras, mapa, música, oração, palestra, piada, pintura, poema, produção textual escrita, produção textual multissemiótica, produção textual oral, propaganda, redação escolar, reportagem, símbolos natalinos, verbete de dicionário, vídeo. Nesse conjunto de dados, há a predominância dos gêneros escritos (15) e multissemióticos (15), acrescidos de 7 (sete) gêneros orais ${ }^{1}$.

Na perspectiva bakhtiniana, os gêneros discursivos secundários (práticas complexas) são ideológicos e surgem em condições de convívio cultural mais complexo e relativamente desenvolvido e organizado e, geralmente, são escritos ou multissemióticos. A exemplo, biografia e palestra. Os gêneros discursivos primários surgem em condições de comunicação discursiva imediata e são orais, em sua maioria, por exemplo, piada. Portanto, o gênero discurso está relacionado essencialmente à natureza do enunciado.

${ }^{1}$ Adotamos o termo 'produção textual' para os textos-enunciados que não foram trabalhados numa perspectiva de gênero discursivo pelas(os) próprias(os) docentes em suas práticas pedagógicas, portanto, não os nomeamos, pois eles eram registrados como textos. No entanto, pressupomos que, nessas produções textuais, os sujeitos do processo de interação verbal têm a palavra e o diálogo, que funcionam para resgatar a história e inventar o cotidiano. Assumindo isso, o(a) aprendiz é produtor(a) de seu próprio conhecimento, como um ser capaz de confrontar conhecimentos concebidos e construir novos a partir dos embates (Geraldi, 2013). Com isso, as produções escritas, multissemióticas e orais são textos-enunciados trabalhados no espaço escolar, sem deixar de ser meio/modo de interação verbal, pois, há sim diálogo entre os sujeitos participantes do processo educativo. 
Para além disso, Rojo e Barbosa (2015, p.27) afirmam que os gêneros discursivos "são entidades da vida". Diante disso, constatamos que no projeto discursivo das aulas observadas, a prática docente e as condições em que ela se realiza não estão voltadas de forma constante ao reconhecimento do cotidiano do estudante - base do trabalho inicial com os gêneros do discurso - pois há uma preocupação em trabalhar gêneros complexos/ideológicos escolarizados, os quais não são encontrados no cotidiano das crianças, das(os) adolescentes e das(os) jovens.

Tal constatação revela mais uma vez que a escola, como principal agência de letramento, assume a responsabilidade de alfabetizar e letrar por meio de práticas sociais de leitura, escrita, oralidade e multissemióticas complexas e distanciadas da vida das(os) estudantes, desprivilegiando suas vivências. Diante disso, um dos desafios a ser enfrentado pelas escolas públicas participantes do estudo é a valorização das práticas já contidas na comunidade-sejam elas orais, escritas ou multissemióticas- e usá-las como meio para ampliar as suas próprias práticas e apropriar-se das práticas complexas.

No entanto, é importante lembrar que à medida em que as condições de convívio cultural ficam mais complexas, as ideologias se tornam mais específicas e formais e surgem nas condições de um convívio cultural mais complexo e relativamente organizado, como no campo educacional. Por isso, a escolha da escola não é aleatória, mas uma resposta dialógica ao que se é esperado dela.

Conforme Bakhtin (2011, p.297): "cada enunciado é pleno de ecos e ressonâncias de outros enunciados com os quais está ligado pela identidade da esfera da comunicação discursiva. Cada enunciado deve ser visto antes de tudo como uma resposta aos enunciados precedentes de um determinado campo [...]" [grifo do autor]. Logo, a predileção pela aula expositiva pode ser uma resposta ao conjunto de outros enunciados que dialogam direta e intrinsecamente com as condições de trabalho oportunizadas às(aos) docentes, que também são interpeladas(os) pelas concepções de educação, escola, ensino, aprendizagem, língua(gem), trabalho pedagógico, estudante, professor e até mesmo a própria concepção e tipo de aula.

Ressaltamos que não diferentemente da escola de Educação Bási- 
ca, nas instituições de ensino superior, a aula expositiva também é o contexto formativo mais vivenciado pelas(os) professoras(es) em situações de letramento acadêmico, ou seja, quando estão em formação profissional. Portanto, essa repetição nada mais é do que a reafirmação da resposta que se espera dessa esfera de comunicação: científica, acadêmica e educacional.

$\mathrm{Na}$ atual pandemia gerada pelo Covid-19, é preciso pensar como esse gênero discursivo pode e deve ser impactado em nossos espaços educativos. Seria importante nos perguntarmos: a aula expositiva pode dar conta das atuais demandas dos processos de ensino e aprendizagem em nossas escolas da Educação Básica em tempos de ensino remoto emergencial? Com os atravessamentos advindos do uso das tecnologias da informação e comunicação, as aulas expositivas serão ainda possíveis, viáveis, dialógicas e responsivas?

Ainda que tenha sido a aula expositiva o meio de promoção dos processos de ensino e aprendizagem, é nela que foram trabalhados aqueles trinta e sete gêneros discursivos e também foram contempladas, no trabalho escolar, as seguintes esferas: científica, acadêmica e educacional (56); lúdica (14); ficcional (11); religiosa (9); interpessoal (6); artística (4); jornalística (3); cotidiana (1); cultura (1); humorística (1); publicitária (1), totalizando 107 (cento e sete ocorrências). Logo, esses campos apontam o quanto a escola tem sido um espaço-tempo eminentemente ideológico e complexo em sua natureza.

Diante disso, o trabalho docente na escola da Educação Básica é incitado à contemplação, em seu cotidiano, da diversidade dos gêneros discursivos, tendo como princípio do trabalho com textos-enunciados o cotidiano dos sujeitos. A prática docente, na instituição escolar, pode auxiliar de modo significativo (as)os estudantes no processo de produção textual, a exemplo, abandonar as tradicionais redações escolares (esvaziadas de sentido e de função) e criar ambientes de aprendizagem com os distintos gêneros discursivos prenhes de sentido e função social: manifestos, carta aberta, resenhas, vlogs, blogs, vídeos, tutoriais... Ou seja, as vivências da realidade social são contextos de implementação de processos formativos a partir das escolhas da escola, de suas(seus) professoras(es), de suas(seus) 
estudantes e familiares para qualificar o tempo pedagógico da escola como um tempo de produção, transformação e ressignificação dos conhecimentos estudados, aprendidos e problematizados.

Desse modo, quanto mais contato as(os) estudantes têm com distintos gêneros do discurso cotidianamente, produzindo-os e fazendo-os circular e serem recebidos por diversos interlocutores, mais se amplia suas possibilidades de participação ativa, efetiva e responsiva em distintos campos da atividade humana (cotidiano, público, jornalístico, científico, acadêmico, escolar etc) e, portanto, propicia-se uma maior apropriação de diferentes letramentos (escolar, local, vernacular, dominante etc.).

Então, o trabalho com os gêneros discursivos só tem sentido num ambiente educativo que priorize os multiletramentos. Nessa prática docente, não cabe o foco nos tipos textuais, mas sim em metodologias de ensino que reconheçam e valorizem os gêneros do discurso como experiências de aprendizagens necessárias às(aos) discentes dos anos iniciais do Ensino Fundamental. Pois, alfabetizar letrando, por meio dos gêneros discursivos, deve ser um compromisso coletivo da escola.

\section{Considerações finais}

Esse estudo possibilitou compreender a escola como lugar público de implementação da educação, como dependente essencial do trabalho docente exercido em articulação com os sujeitos que estão dentro e fora desse espaço. Portanto, a prática docente exige diálogo com a sociedade. Para que isso aconteça, duas questões são fundantes: as condições de trabalho e a formação de professoras(es). Essa dupla demanda vem, ao longo da história da educação brasileira, consistindo em constantes desafios no âmbito das políticas públicas educacionais. Se de um lado, o Estado (como responsável legal) não tem conseguido dar conta dessas duas responsabilidades eficiente e totalmente. De outro lado, há todo um esforço por parte dos movimentos sociais e de educadoras(es), juntamente com as universidades públicas brasileiras, em diálogo com o Estado (como 
coadjuvante), em promover políticas locais/regionais que auxiliem no atendimento de critérios de qualidade para superar os desafios apresentados na educação escolar pública do Brasil. Nesse contexto, o Programa Rede UNEB 2000 foi efetivo no combate às disparidades presentes na formação de professoras(es) na região Oeste da Bahia.

No âmbito da escola pública, a prática docente necessita ser problematizada. Ainda há muitos desafios a serem enfrentados, os quais só podem ser superados e/ou amenizados mediante à participação ativa de todas as pessoas comprometidas com a educação pública de qualidade social. Por isso, é importante que as políticas públicas educacionais, em âmbitos federal, estaduais e municipais - articulem-se constante e organizadamente junto com os demais espaços colaborativos somados à sociedade civil (a exemplo, os conselhos de educação dos distintos entes federativos) para dar conta daquelas duas questões latentes, bem como das especificidades que a docência, o ensino, a aprendizagem, a escola e a aula demandam por meio do acontecimento da própria prática docente.

Além disso, é sabido que a língua(gem) acontece por meio de múltiplos gêneros orais, escritos e multissemióticos produzidos e proferidos pelos integrantes em distintos campos da atividade humana (esferas de circulação, produção e recepção de discursos). Portanto, é também por meio da prática docente -nos processos de ensino e aprendizagem dos gêneros do discurso- que se pode atender os desejos e as demandas dos sujeitos envolvidos com o processo educativo, os quais utilizam as práticas sociais de leitura, escrita, oralidade e multissemioses para (re)construir e atuar no cenário social de modo social, cultural e político.

A discussão proposta leva a compreensão de que a maior presença da aula expositiva dialoga com as condições sociais, econômicas e pedagógicas constitutivas da prática docente aqui problematizada. É importante ressaltar que esse gênero discursivo pode inibir as possibilidades de criar ambientes formativos dialógicos e acolhedores das diversidades advindas das experiências das(os) estudantes, que são sujeitos produtores de culturas e transformadores de suas próprias realidades. Ainda assim, é esse mesmo gênero que funciona como resposta pedagógica de vanguarda para o trabalho com 
outros gêneros discursivos.

Mediante o estudo apresentado, ficou evidente que a produção da prática docente e a aula expositiva como lugar de enunciação são fenômenos complexos e exigem uma amplitude e multiplicidade de olhares para compreender os mecanismos engendrados nas escolas públicas participantes desse estudo. Além disso, há o reconhecimento de que é na aula, no nosso caso, na aula expositiva, que a prática docente está sendo produzida, acentuadamente.

Portanto, a prática docente deve estar em permanente movimento, não é algo pronto e estático, não há controle e/ou previsibilidade, pois estamos tratando de relações interpessoais estabelecidas na experiência cotidiana do processo de ensino e aprendizagem, produção de conhecimentos e saberes, os quais são repletos de mistérios, desafios e conquistas.

\section{Referências}

Bakhtin, M. M. (2011). Estética da criação verbal. Trad. Paulo Bezerra. São Paulo, Brasil: Editora WMF Martins Fontes.

Bakhtin, M. M. (2017). Marxismo e Filosofia da Linguagem. São Paulo Brasil: Editora 34.

Carvalho, M. R. V. (2018). Perfil do professor da educação básica. Brasília, DF, Brasil: Instituto Nacional de Estudos e Pesquisas Educacionais Anísio Teixeira.

Freire, P. (2017). A importância do ato de ler: três artigos que se completam. São Paulo, Brasil: Cortez.

Geraldi, J. W. (2013). Da redação à produção de textos. In L. Chiappini (Ed.). Aprender e ensinar com textos (pp.17-24). São Paulo, Brasil: Cortez.

LEI N ${ }^{\circ} 9.394$ de Diretrizes e Bases da Educação. Diário Oficial da União, ano CXXXIV, nº 248, seção I. Brasília, 23 de dezembro de 1996.

Lemke, J. L. (2010). Letramento metamidiático: transformando significados e mídias. Trabalhos em Linguística Aplicada, 49, 455-479.

Lüdke, M. e André, M. E. D. A. (2016). Pesquisa em educação: abordagens qualitativas. São Paulo, Brasil: EPU. 
Macedo, E. F. (2019). Fazendo a Base virar realidade: competências e o germe da comparação. Revista Retratos da Escola, Brasília, 13, 39-58.

Minayo, M. C. S. (2016). Pesquisa social: Teoria, método e criatividade. Petrópolis, Brasil: Vozes.

Pereira, F. E. L. (2012). Aula expositiva: um estudo linguístico. Anais do Congresso Norte Nordeste de Pesquisa e Inovação - CONNEPI. Palmas, Brasil: CONNEPI.

Pimenta, S. G. e Lima, M. S. L. (2019). Estágios supervisionados e o Programa Institucional de Bolsa de Iniciação à Docência: duas faces da mesma moeda? Revista Brasileira de Educação, 24, 1-20.

Pinar, W. (2016). Estudos Curriculares: ensaios selecionados. Seleção, organização e revisão técnica de Alice Casimiro Lopes e Elizabeth Macedo. São Paulo, Brasil: Cortez.

Rojo, R. H. R. (2012). Pedagogia dos multiletramentos: diversidade cultural e de linguagens na escola. In R. H. R. Rojo y E. Moura (Eds.), Multiletramentos na escola. (pp. 11-31). São Paulo, Brasil: Parábola Editorial.

Rojo, R. H. R. (2014). Gêneros discursivos do Círculo de Bakhtin e multiletramentos. In R. H. R.

Rojo, (Ed.).Escol@ Conectada: Os multiletramentos e as TICS (pp. 13-36). São Paulo, Brasil: Parábola.

Rojo, R. H. R. y Barbosa, J. P. (2015). Hipermodalidade, multiletramentos e gêneros discursivos. São Paulo, Brasil: Parábola Editorial.

Soares, M. (2018). Alfabetização e letramento. São Paulo, Brasil: Contexto.

Recibido: 14.08.2020 Aceptado: 05.02.2021 